\title{
Hyperalimentation in Treatment of Anorexia Nervosa
}

\author{
TAKAKo NAKAZAWA, YoSHIAKI OKADA*, TOSHIO ONISHI, \\ MIZUO AZUKIZAWA AND YUICHI KUMAHARA \\ Department of Medicine and Geriatrics, Osaka University \\ School of Medicine Fukushima-ku, Osaka 553; \\ and Hanwa Senboku Hospital Osaka 593.*
}

\begin{abstract}
Ten patients with anorexia nervosa were treated with intravenous hyperalimentation (IVH) and/or psychotherapy. The five patients were treated with both IVH and psychotheraoy. The five patients were treated with both IVH and psychotherapy. Their body weight rose from $66 \pm 3 \%$ (mean $\pm \mathrm{SE}$ ) to $78 \pm 6 \%$ of their ideal weight during hospitalization, and then to $91 \pm 5 \%$ during ambulatory observation for a period of 6 to 36 months. Another group of 5 patients were treated only with psychotherapy. Their body weight increased $69 \pm 3 \%$ to $73 \pm 1 \%$ of their ideal weight during hospitalization, and then to $78 \pm 1 \%$ during during the observation period at the out-patient department during a period of 6 to 48 months. The former group gained more weight than the latter group during hospitalization $(\mathrm{P}<0.025)$ and during ambulatory observation $(\mathrm{P}<0.025)$, respectively. These results suggest that IVH is one effective remedy for anorexia nervosa and that good results can be expected from IVH and psychotherapy used in combination.
\end{abstract}

Anorexia nervosa is a disorder occuring predominantly in females and characterized by a refusal to eat. According to the report by Crisp et al. (1976) severe anorexia nervosa is becoming more common, and the prevalence in Britain is one severe case in approximately every 200 girls. The patient reveals a distorted attitude toward eating and body image associated with severe weight loss. Though a variety of therapies, including behavior modification (Agras et al., 1974; Halmi et al., 1975), family therapy (Barcai, 1971), tube feeding and bed rest (Crisp, 1965) have been advocated, the treatment of anorexia nervosa is difficult and usually prolonged. In cases of severe malnutrition, a high mortality rate is reported (Bruch, 1971). For these patients, severe weight loss may require somatic treatment during the course of intensive psychotherapy. Nasogastric tube feeding and forced

Received November 13, 1981. bed rest are practiced, but neither has been well accepted by patients. A new technique has become available in the comprehensive treatment of severe malnutrition. This is called intravenous hyperalimentation (IVH). IVH is a method establishing nutritional balance in many cases of severe malnutrition that have internal complications and need rapid improvement in nutrition. Application of IVH to anorectic patients has recently been recommended (Finkelstein, 1972).

It has been well known that the triiodothyronine $\left(\mathrm{T}_{3}\right)$ serum concentration in anorectic patients is significantly lower than that of normal subjects (Miyai et al., 1975; Moshang et al., 1975). Nixon et al. (1980), however, reported that the creatinine height ratio (CHR) is a sensitive quantitive indication of proteincalorie undernutrition in cancer patients. In this article we describe the effect of IVH and psychotherapy on anorectic patients compared to that of psychotherapy without IVH, 
and we discuss the $T_{3}$ and $C H R$ values as an indicator of the nutritional condition in anorexia nervosa.

\section{Materials and Methods}

\section{1) Subjects}

Ten female patients, 14 to 27 years old, were studied. They demonstrated unequivocal signs of primary anorexia nervosa, according to the criteria of Feighner et al. (1972). Five patients were treated with IVH and psychotherapy (Group A) and the remaining 5 patients with psychotherapy only (Group B). The allocation of patients to the IVH therapy was mainly based on patients' acceptance. The length of hospitalization of group A was $8.8 \pm 1.3$ weeks and that of group B was $4.8 \pm 1.2$ weeks, and for the group A patients the duration of IVH was $4.2 \pm 1.0$ weeks. Table 1 indicates the clinical features and laboratory findings related to the patients. No significant difference was noted in age, duration of amenorrhea, weight loss and percentage of ideal weight between groups $\mathrm{A}$ and $\mathrm{B}$. Laboratory tests revealed no abnormalities except a low level of BMR and $\mathrm{T}_{3}$, and the diagnosis of anorexia nervosa was established during hospitalization. The basal BMR, $\mathrm{T}_{3}$ and weight of group $\mathrm{A}$ were lower than those of group $B$.

\section{2) Hyperalimentation}

In IVH a silicon rubber catheter (Toyo Hospital Supply Co.,) was inserted into the infraclavicular subclavian vein and threaded into the superior vena cava. The nutrient solution was infused continuously. The basic solution was composed of $20 \%$ glucose, $4 \%$ amino acid, electrolytes, minerals and vitamins, but no lipid emulsion. The total volume was $40-50 \mathrm{cc} / \mathrm{kg} /$ day. Calorie intake was initially $30-40 \mathrm{Cal} / \mathrm{kg} /$ day then gradually increased to $60-70 \mathrm{Cal} / \mathrm{kg} /$ day. Oral intake of food was prohibited for the first 1-2 weeks and then allowed. The food intake was started at a level of 400-600 Cal/day.

\section{Results}

The patients in group $\mathrm{A}$, whose weight ranged from 28.6 to $35.5 \mathrm{~kg}$ and gained 3.6 to $10.9 \mathrm{~kg}(5.7 \pm 1.3 \mathrm{~kg})$ during the IVH and psychotherapy treatment. They also gained 1.0 to $19.5 \mathrm{~kg}(6.5 \pm 3.4 \mathrm{~kg})$ during a follow-up term of 6 to 36 months after discharge. The percentage of their body weight to their ideal weight rose from a mean of $66 \pm 3 \%$ up to




$78 \pm 6 \%$ during hospitalization and to a mean of $91 \pm 5 \%$ during the ambulatory follow-up. On the other hand, the 5 patients in group $\mathrm{B}$, whose weight ranged from 31.5 to $36.0 \mathrm{~kg}$, gained 0 to $5.5 \mathrm{~kg}(2.1 \pm 1.2 \mathrm{~kg})$ during hospitalization and gained 0 to $4.5 \mathrm{~kg}(2.5 \pm 0.8$ $\mathrm{kg}$ ) while they were observed in the out- patient department (OPD) for a period of 6 to 48 months. The percentage of their body weight to their ideal weight rose from $69 \pm 3 \%$. up to $73 \pm 1 \%$ during hospitalization and to $78 \pm 1 \%$ while they were observed in the OPD (Table 1). The patients in group A gained more weight than those in group B during


T3ng/dl

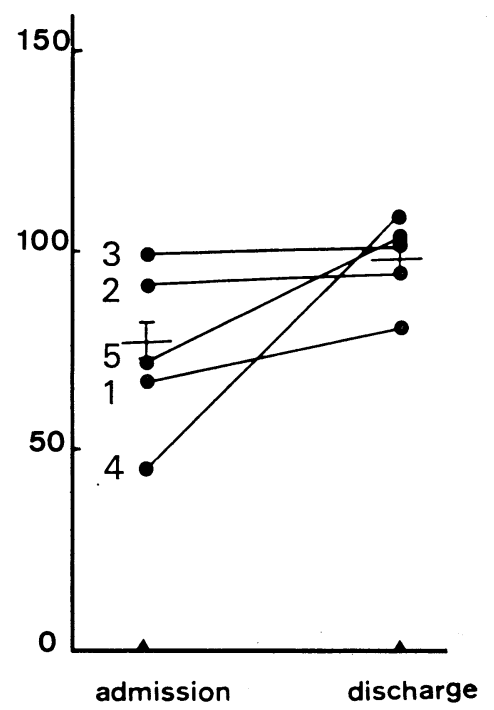

CHR

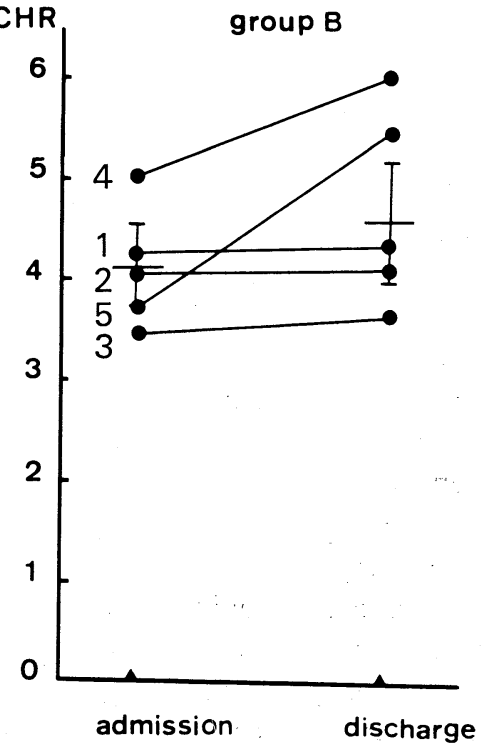

Fig. 1. Effects of intravenous hyperalimentation (I VH) on levels of $T_{3}$ and creatinine height ratio (CHR) in the patients. In group A treated with IVH and psychotherapy, the mean level of $T_{3}$ rose from $65 \pm 15 \quad($ mean $\pm \mathrm{SE})$ to $123 \pm 17 \mathrm{ng} / \mathrm{dl} \quad(\mathrm{P}<0.001)$ and that of CHR increased from $3.0 \pm 0.4$ to $4.3 \pm 0.3$ $\mathrm{mg} / \mathrm{cm} \quad(P<0.001)$ In group $\mathbf{B}$ treated with psychotherapy only, the mean level of $\mathrm{T}_{3}$ rose from $75 \pm 8$ to $95 \pm 5 \mathrm{ng} / \mathrm{dl}$ (NS) and that of $\mathrm{CHR}$ changed from $4.2 \pm 0.4$ to $4.7 \pm 3.6$ $\mathrm{mg} / \mathrm{cm}$ (NS) during hospitalization. The number beside the closed circle indicates the patient's number in table 1 . 
hospitalization $(\mathrm{P}<0.025)$ and during ambulatory observation $(\mathrm{P}<0.025)$. We investigated whether the levels of $\mathrm{T}_{3}$ and $\mathrm{CHR}$ were improved by IVH. In group $\mathrm{A}$, the mean $\mathrm{T}_{3}$ level rose significantly from $64 \pm 15$ to $123 \pm$ $17 \mathrm{ng} / \mathrm{dl}(\mathrm{P}<0.001)$ after $4.2 \pm 1.0$ weeks of IVH therapy. The $T_{3}$ level of a normal young female is 100 to $200 \mathrm{ng} / \mathrm{dl}$. The mean CHR level rose significantly from $3.0 \pm 0.4$ to $4.3 \pm$ $0.3 \mathrm{mg} / \mathrm{cm}(\mathrm{P}<0.001)$. The normal range of CHR is 4.5 to $7.0 \mathrm{mg} / \mathrm{cm}$. In group $\mathrm{B}$, the mean level of $T_{3}$ increased from $75 \pm 8$ to $94 \pm$ $5 \mathrm{ng} / \mathrm{dl}$ during hospitalization and the CHR level changed from $4.2 \pm 0.4$ to $4.7 \pm 0.6 \mathrm{mg} /$ $\mathrm{cm}$, as shown in Fig. 1.

\section{Discussion}

The treatment of anorexia nervosa is difficult, and patients often relapse. According to Lucas et al. (1976), severe anorexia nervosa has a high mortality rate. Sometimes it is not sufficient to treat an intractable anorectic patient with psychotherapy only. In cases of severe malnutrition, it is necessary to improve metabolism immediately before psychotherapy is started. In our study, two patients in group A were too cachectic to respond to any mental approach, and their weight gradually decreased in spite of hospitalization until IVH therapy was started. It is important to decide on the indications of IVH therapy. We suggest the following indications for IVH, 1) life threatening weight loss, 2) no tendency to weight increase in spite of hospitalization and psychotherapy. Maloney and Farrell (1980) reported that good results can be expected by treating severe anorexia nervosa with hyperalimentation and psychotherapy. Furthermore, they also reported that the good effect of IVH continued during the follow-up term as the patients gained more and more weight. Our patients in group A also continued to gain more weight than the patients in group $B$ after discharge. These results suggest that the effect of IVH on anorexia nervosa is not transient and it is important to improve metabolism rapidly during the hospitalization of these patients. Radical problems related to the illness cannot always be solved with IVH and psychotherapy including behavior modification, but family therapy and other psychological treatment should be continued in an interdisciplinary approach.

Low levels of $\mathrm{T}_{3}$ and CHR were markedly improved with IVH. In anorexia nervosa, it is uncommon to find hypoproteinemia or hypoalbuminemia in spite of severe malnutrition. In group A patients $\mathrm{T}_{3}$ and $\mathrm{CHR}$ levels rose in parallel with the increase in weight during IVH, and the levels of No. 4 and No. 5 patients in group $\mathrm{B}$ also rose during the treatment. On the other hand, in No. 1, 2 and 3 patients in group B who did not gain weight significantly, no significant change in the levels was seen. Our data indicate that $T_{3}$ and CHR as well as weight are good measures of nutrition in patients with anorexia nervosa.

These results suggests that IVH is not a panacea for anorexia nervosa, but IVH is worth using on intractably severe anorectic patients who need rapid improvement in metabolism for a time during hospitalization.

\section{Acknowledgements}

We are grateful to Miss Noriko Iwashita for her help in preparing the manuscript.

This work was supported in part by Research Grants from the Ministry of Education, Sciench and Culture, and the Ministry of Health and Welfare of Japon.

\section{References}

Agras, W. S., D. H. Barlow, H. N. Capin, G. G. Abel and H. Leitenberg (1973). Behavior modification of anorexia nervosa. Arch. Gen. Psychiatry 30, 279285.

Barcai, A. (1971). Family therapy in the treatment of anorexia nervosa. Am. J. Psychiatry 28, 286-290.

Bruch, H. (1971). Death in anorexia nervosa. Psychosom. Med. 33, 135-144.

Bruch, H. (1974). Perils of behavior modification in treatment of anorexia nervosa. JAMA 230, 1419. 
Crisp, A. H. (1965). A treatment regimen for anorexia nervosa. B. J. Psychiatry 112, 505-512.

Crisp, A. H., R. L. Palmer and R. S. Kalucy (1976). How common is anorexia nervosa? A prevalence study. B. J. Psychiatry 128, 549-554.

Feigner, J. P., E. Robins, S. B. Guze, R. A. Woodruff, G. Winokur and R. Munoz (1972). Diagnostic criteria for use in psychiatric research. Arch. Gen. Psychiatry 26, 57-63.

Finkelstein, B. A. (1972). Parenteral hyperalimentation in anorexia nervosa. JAMA 219, 217.

Halmi, K. A., P. Powers and S. Cunningham (1975). Treatment of anorexia nervosa with behavior modification. Arch. Gen. Psychiatry 32, 93-96.

Lucas, A. R., J. W. Duncan and V. Piens (1976). The treatment of anorexia nervosa. Am. J. Psychiatry 133, 1034-1038.
Maloney, M. J. and M. K. Farrell (1980). Treatment of severe weight loss in anorexia nervosa with hyperalimentation and pyschotherapy. Am. J. Psychiatry 137, 310-314.

Miyai, K., T. Yamamoto, M. Azukizawa, K. Ishibashi and Y. Kumahara (1975). Serum thyroid hormones and thyrotropin in anorexia nervosa. J. Clin. Endocrinol. Metab. 40, 334-338.

Moshang, T. Jr., J. S. Parks, L. Baker, V. Vaidya, R. D. Utiger, A. M. Bongiovanni and P. J. Snyder (1975). Low serum trilodothyronine in patients with anorexia nervosa. J. Clin. Endocrinol. Metab. 40, 470-473.

Nixon, D. W., S. B. Heymsfield, A. E. Cohen, M. H. Kutner, J. Ansley, D. H. Lawson and D. Rudman (1980). Proteincaloric undernutrition in hospitalized cancer patients. Am. J. Med. 68, 683-690. 